\title{
Pulmonary function at rest and during exercise following bagassosis
}

\author{
G. J. MILLER, C. E. D. HEARN, and R. H. T. EDWARDS
}

The Medical Research Council's Epidemiology Unit, University of the West Indies, Mona, Jamaica; The Occupational Health Service, Caroni Limited (Tate and Lyle Limited), Couva, Trinidad; and the Department of Medicine, Royal Postgraduate Medical School, Hammersmith Hospital, London, W12, England

Miller, G. J., Hearn, C. E. D., and Edwards, R. H. T. (1971). Brit. J. industr. Med., 28, 152-158. Pulmonary function at rest and during exercise following bagassosis. Lung function and exercise responses were investigated in two groups of Indian bagasse workers to assess whether there were any permanent sequelae following regular exposure to bagasse dust in a group of 12 men who had developed bagassosis and a group of six who had not. Ventilatory capacity, lung volumes, single breath carbon monoxide transfer factor(TF), diffusion capacity of the alveolarcapillary membrane $(\mathrm{Dm})$, and volume of blood in the pulmonary capillaries $(\mathrm{Vc})$ were measured, and then exercise responses were investigated with a cycle ergometer. The ventilatory response to hypercapnia was assessed by a modified re-breathing method.

The group of 12 patients had small but significant reductions in lung volumes, TF, and $\mathrm{Dm} 7$ to 10 years after the acute episode. The ventilatory responses to exercise and hypercapnia were increased but exercise capacity was normal and limited by the cardiovascular responses. Exercise hyperventilation was the likely explanation for the exertional dyspnoea in this group.

Six of a group of workers who had been regularly exposed to mouldy bagasse dust without developing bagassosis and had a significant reduction in ventilatory capacity during exposure were found to have normal lung function and exercise responses two years after withdrawal from bagasse.

Immunological reactivity to an extract of Thermoactinomycetes vulgaris was found to have subsided after withdrawal from bagasse dust, although it can persist for six years. In a single case, disodium cromoglycate failed to suppress the late systemic reaction provoked by the inhalation test.

Bagasse is the fibrous residue of sugar-cane after sugar extraction. Inhalation of bagasse dust contaminated by thermophilic actinomycetes, particularly Thermoactinomycetes vulgaris (Hearn and Holford-Strevens, 1968; Hargreave, Pepys, and Holford-Strevens, 1968), may give rise to the disease known as bagassosis, in which there is a hypersensitivity reaction in the peripheral bronchopulmonary tree. There is profound shortness of breath, cough, malaise, weight loss, and sometimes fever during the acute episode. Crepitations are a constant feature and chest radiographs usually show fine micronodular shadowing (Hearn, 1968a). Lung volumes, ventilatory capacity, and gas transfer are reduced (Pierce, Nicholson, Miller, and Johnson, 1968).

The acute disease is self-limiting and spontaneous symptomatic recovery occurs within six weeks after withdrawal from exposure to mouldy bagasse dust (Hearn, 1968a; Weill, Buechner, Gonzalez, Herbert, Aucoin, and Ziskind, 1966). The concept of a chronic form of the disease originated from a report 
of two cases of pulmonary fibrosis among workers previously exposed to bagasse dust (Hunter and Perry, 1946) and Weill et al. (1966) have reported two cases of airways obstruction among 20 workers with antecedent acute bagassosis. Protracted impairment of lung function following clinical and radiographic recovery from bagassosis was reported by Pierce et al. (1968), who followed their patients for periods ranging from 11 to 27 months after the acute episode.

Between 1959 and 1963, 17 subjects developed bagassosis while working in a bagasse baling department of a sugar factory in Trinidad. The clinical features, ventilatory function, and immunological aspects of this outbreak during and shortly after the acute episode have been reported previously (Hearn, 1968a; Hearn and Holford-Strevens, 1968). Lung function, response to exercise, and degree of reactivity to an extract of Thermoactinomycetes vulgaris have now been assessed 6 to 10 years after the acute episode to determine whether any residual pulmonary disability, limitation of exercise capacity, or sensitivity to the allergen has persisted.

Hearn (1968a) found that the ventilatory capacity of men being continuously exposed to mouldy bagasse dust and who had not shown any sign of developing bagassosis was nevertheless significantly lower than that of a control group. Six of the most heavily exposed subjects have been re-examined three years after their last exposure to bagasse dust for evidence of impaired lung function.

\section{Subjects and methods}

All subjects were Indian men, descendants of indentured immigrants brought to Trinidad between 1844 and 1917 from two ports of exit, Calcutta and Madras.

The 12 patients who had had bagassosis were those of the original 17 who had shown well-marked reactions to inhalational provocation with an extract of Thermoactinomycetes vulgaris. Three of the remainder had no reaction, and two had not been tested. The onset of the disease had been acute in two and insidious in ten. The duration of disability had averaged six weeks and the time taken for clinical signs to resolve had varied from four weeks to three months. Radiographic changes had taken between 6 and 21 (average 8) weeks to clear. Following recovery all patients have remained fully employed and apparently in good health. They will be referred to as group $\mathbf{B}$.

The six workers who were regularly exposed to mouldy bagasse dust without developing bagassosis were fully employed in other jobs and appeared to be healthy. These regular workers are referred to as group $\mathbf{R}$.

\section{Clinical evaluation and anthropometry}

The medical history and present state of health was assessed by one investigator (C.E.D.H.) with a standardized questionnaire, after which subjects had a medical examination. Haemoglobin concentration was measured on whole blood using the A. O. Spencer haemoglobin meter (Elwood and Jacobs, 1966).

Respiratory symptoms were assessed by one investigator (G.J.M.) using the revised form of the Medical Research Council's questionnaire for respiratory symptoms (1966) $)^{1}$, and an estimate of the habitual level of activity was made with a standardized questionnaire which graded activity on a four-point scale.

Anthropometric measurements were taken by one observer (R.H.T.E.) with the subjects wearing shorts only, in the manner recommended by the Human Adaptability Sub-committee of the International Biological Programme (Weiner and Lourie, 1969).

\section{Lung function}

All laboratory studies were made in a room where the ambient temperature ranged from $21^{\circ}$ to $31^{\circ} \mathrm{C}$ and relative humidity between $70 \%$ and $80 \%$. The forced expiratory volume in one second $\left(\mathrm{FEV}_{1.0}\right)$ and forced vital capacity (FVC) were measured with the McDermott dry spirometer (Collins, McDermott, and McDermott, 1964), the subjects being seated. Values for each subject were obtained from the mean of three technically satisfactory performances after two practice attempts. Total lung capacity (TLC) and its subdivisions, vital capacity (VC) and residual volume (RV), were measured with a spirometer using the closed-circuit helium dilution method. The apparent volume of distribution of a single breath of helium taken up to TLC, expressed as a fraction of TLC measured by the rebreathing method, was used as an index of the distribution of ventilation. Gas volumes are expressed at body temperature and pressure saturated with water vapour (litres BTPS). The single breath carbon monoxide transfer factor (TF) was measured with an automatic apparatus (Meade, Saunders, Hyett, Reynolds, Pearl, and Cotes, 1965) and partitioned into its two components, the diffusion capacity of the alveolar-capillary membrane $(\mathrm{Dm})$ and the volume of blood in the pulmonary capillaries (Vc), by measuring TF at alveolar oxygen tensions of approximately $100 \mathrm{~mm} \mathrm{Hg}$ and 500 $\mathrm{mm} \mathrm{Hg}$, using the method of Roughton and Forster (1957). Subjects were requested not to smoke for 12 hours before the test to ensure a negligible back tension of carbon monoxide in alveolar capillary blood.

\section{Ventilatory response to $\mathrm{CO}_{2}$}

The ventilatory response to hypercapnia was assessed in all patients by a modified re-breathing method (Read, 1967 ) with the seated subject re-breathing from a bag-in-abottle containing 5 litres of $7 \%$ carbon dioxide in oxygen. Ventilation and $\mathrm{Pco}_{2}$ were measured at half-minute intervals. Tidal gas was sampled at a rate of $1 \mathrm{litre} / \mathrm{min}$, passed through a drying tube, an infra-red $\mathrm{CO}_{2}$ analyser (Godart URAS), and a paramagnetic $\mathrm{O}_{2}$ analyser (Servomex) and returned to the re-breathing bag. The gas analysers were calibrated before and after each

1Obtainable from W. J. Holman Ltd, Dawlish, Devon, England. 
run with dry gas mixtures previously analysed with a Scholander apparatus. Expired volumes were calculated from the time for $\mathbf{1 0}$ or $\mathbf{2 0}$ litres of air displaced from the bottle to pass through a dry gas meter (ParkinsonCowan CD4), and respiratory rate was calculated from the number of complete breaths taken during this period. The $\mathrm{Po}_{2}$ at the end of the run was above $180 \mathrm{~mm} \mathrm{Hg}$, indicating that hypoxaemia was not contributing to the hyperpnoea in these studies.

\section{Exercise response}

Sixteen subjects were exercised on a cycle ergometer (Monark) maintaining a pedal frequency of 60 per minute indicated by a metronome. The power load was increased progressively every three minutes through three submaximal work loads covering the heart rate range of 100 to 150 beats per minute. The exact pedal frequency was checked at minute intervals by timing 15 pedal actions. Subjects breathed through a low resistance $\mathbf{J}$ type respiratory valve with a dead space of $170 \mathrm{ml}$, inspired gas being delivered through a 3-cm smooth-bore tubing from a dry gas meter and expired gas being similarly conducted to a mixing chamber of $2 \cdot 2$ litres capacity. Air was delivered to the inspiratory circuit from an electric blower to compensate for the resistance of the gas meter to air flow.

Measurements of inspiratory minute volumes, frequency of breathing, and analyses of gas sampled from the mixing chamber were made at minute intervals as in the study of the ventilatory response to hypercapnia. Inspiratory and expiratory volumes were assumed to be equal and no correction was applied for the dead space of the apparatus. An earlier study of exercise responses of healthy young adults, using an identical technique in duplicate, confirmed the reproducibility of the method (Edwards, Miller, Hearn, and Cotes, 1969b).

The indices of submaximal exercise chosen were the cardiac frequency $\left(\mathrm{CF}_{\mathbf{1 . 5}}\right)$ and ventilation $\left(\dot{\mathrm{VE}}_{\mathbf{1 . 5}}\right)$ at an oxygen consumption of 1.5 litres per minute standard temperature and pressure dry (STPD) derived by interpolation of the rectilinear portions of the cardiac frequency: oxygen consumption $\left(\dot{\mathrm{V}} \mathrm{O}_{2}\right)$, and ventilation: $\dot{\mathrm{VO}}_{2}$ relationships, respectively (Weiner and Lourie, 1969). Maximal oxygen consumption was obrained by extrapolation of the rectilinear portions of the $\mathrm{CF}: \dot{\mathrm{VO}}_{2}$ relationship to a maximum heart rate of 176 per minute as judged from the mean age of the group. The pattern of breathing adopted during exercise and during hypercapnia was assessed by estimating the interpolated tidal volume at a ventilation of 30 litres per minute $\left(\mathrm{VT}_{\mathbf{3 0}}\right)$ (Cotes, Johnson, and McDonald, 1970).

\section{Immunological reactivity}

The residual immunological reactivity of seven subjects previously shown to be sensitive to an extract of Thermoactinomycetes vulgaris was re-assessed by repeating the inhalation test and employing an identical technique. The extract was delivered at a concentration of $10 \mathrm{mg} / \mathrm{ml}$ using a Wright nebulizer and oxygen at a pressure of $20 \mathrm{lb} / \mathrm{in}^{2}\left(138 \mathrm{KN} / \mathrm{m}^{2}\right)$ (Williams, 1963). This method was shown to be safe and acceptable for these patients when their reactivity was initially assessed (Hearn and Holford-Strevens, 1968), and it was likely that reactivity would have subsided with time. The initial and present inhalation tests were supervised by the same investigator
(C.E.D.H.). Oral temperature, the $\mathrm{FEV}_{1.0}$ and FVC were measured hourly on the day before provocation and repeated on the day of the test.

\section{Analysis of results}

Predicted normal values for the $\mathrm{FEV}_{1.0}$ and FVC were calculated from the following multilinear regression equations derived from an earlier study of the ventilatory capacity of 100 male Indian workers in Trinidad (Hearn, 1968b).

$\mathrm{FEV}_{1.0}$ (litres) $=0.098 \times$ height (in.) $-0.026 \times$ age $(\mathrm{yr})-2 \cdot 50(\mathrm{RSD}=0.36)$

FVC (litres) $=0.13 \times$ height (in.) $-0.027 \times$ age $(\mathrm{yr})-$ $3.96($ RSD $=0.41)$

Multilinear regression equations describing the lung volumes and indices of gas transfer of healthy Indian subjects in the Caribbean are not available. However, the ethnic difference in lung volumes of subjects of African and Indian descent is small and there is no difference in TF, Dm, or Vc (Edwards et al., 1969b). Therefore prediction equations describing the lung volumes and indices of gas transfer of healthy subjects of African origin in the Caribbean have been employed (Miller, 1970). Where a variable was a function of age and height (FEV 1.0, FVC, RV, TF, Dm) differences between the means of measured values and predicted values for each group were tested by bivariate covariance analysis. For Vc, the indices of exercise responsiveness, and ventilatory response to hypercapnia the differences between means of the measured values for group $B$ and group $\mathbf{R}$ were tested using a $t$ test or, where variances were unequal, an approximation of the $t$ test (Bailey, 1959). Differences were considered significant if the likelihood of occurrence by chance was less than $5 \%(\mathrm{P}<0.05)$.

\section{Results}

Both groups were of similar socio-economic status and had similar customary levels of activity. Group B mentioned moderate dyspnoea on exertion more frequently than group $R$ but there were no other respiratory symptoms of note.

\section{Anthropometry}

Group B was slightly taller and more obese than group $\mathbf{R}$, judging by skinfold thickness and weight/ height ratio. Otherwise the groups resembled each other closely (Table 1).

\section{Lung volumes}

The $\mathrm{FEV}_{1.0}$ and FVC in group $\mathrm{B}$ were significantly smaller than predicted, whereas they were similar to predicted normal values in group $\mathbf{R}$. Both groups had residual volumes similar to predicted normal values (Table 2). The fraction of the FVC expired in one second $\left(\mathrm{FEV}_{1.0} / \mathrm{FVC}^{\circ}\right)$ for group B (80.2\%, SD $1 \cdot 1)$ and group $R(80.5 \%$, SD $1 \cdot 0)$, and the index of distribution of ventilation $(1.0$, range 0.96 to $1.03 ; 0.99$, range 0.94 to 1.03 , respectively) were normal and excluded airways obstruction. 
TABLE 1

ANTHROPOMETRIC DATA

\begin{tabular}{|c|c|c|c|c|}
\hline \multirow{2}{*}{ Index } & \multicolumn{2}{|c|}{$\begin{array}{c}\text { Group B } \\
(12 \text { subjects })\end{array}$} & \multicolumn{2}{|c|}{$\begin{array}{c}\text { Group } R \\
\text { (6 subjects) }\end{array}$} \\
\hline & Mean & $S D$ & Mean & $S D$ \\
\hline Age (yr) & 42 & $6 \cdot 5$ & 44 & $7 \cdot 8$ \\
\hline $\begin{array}{l}\text { Haemoglobin } \\
\quad(\mathrm{g} / 100 \mathrm{ml})\end{array}$ & $14 \cdot 5$ & $1 \cdot 5$ & $14 \cdot 1$ & 0.8 \\
\hline Stature (m) & $1 \cdot 67$ & 0.07 & $1 \cdot 62$ & 0.05 \\
\hline$\frac{\text { Sitting height }}{\text { Standing height }}$ & 0.512 & 0.015 & 0.506 & 0.012 \\
\hline Sitting height & & & & \\
\hline$\overline{\text { Sub-ischial height }}$ & 1.005 & 0.063 & 1.023 & 0.050 \\
\hline $\begin{array}{l}\text { Weight (kg) } \\
\text { Weight } / \text { Height } \\
(\mathrm{kg} / \mathrm{m})\end{array}$ & $\begin{array}{l}68 \cdot 2 \\
40 \cdot 82\end{array}$ & $\begin{array}{c}14 \cdot 5 \\
8 \cdot 08\end{array}$ & $\begin{array}{l}62 \cdot 8 \\
38 \cdot 60\end{array}$ & $\begin{array}{c}10 \cdot 2 \\
5 \cdot 65\end{array}$ \\
\hline $\begin{array}{c}\text { Sum of four skinfold } \\
\text { thicknesses }(\mathrm{mm})\end{array}$ & $60 \cdot 4$ & $28 \cdot 6$ & $52 \cdot 8$ & $22 \cdot 2$ \\
\hline $\begin{array}{l}\text { Calf circumference } \\
(\mathrm{cm})\end{array}$ & $35 \cdot 5$ & $3 \cdot 4$ & $35 \cdot 0$ & $2 \cdot 4$ \\
\hline $\begin{array}{l}\text { Upper arm circum- } \\
\text { ference }(\mathrm{cm})\end{array}$ & $29 \cdot 9$ & $3 \cdot 0$ & $30 \cdot 3$ & $2 \cdot 0$ \\
\hline $\begin{array}{l}\text { Thigh circumference } \\
\text { (cm) }\end{array}$ & $52 \cdot 8$ & $6 \cdot 1$ & $51 \cdot 2$ & $4 \cdot 7$ \\
\hline
\end{tabular}

Pulmonary gas transfer

Table 2 shows that group B had a small but significant reduction in gas transfer due to a significant reduction in the diffusion capacity of the alveolar capillary membrane, whereas gas transfer was normal in group R. Group B had a smaller pulmonary capillary blood volume than group $\mathrm{R}$ but the difference was not statistically significant.

\section{Response to exercise}

The ventilatory response to exercise was significantly larger in group B than in group $\mathbf{R}$. Increases in heart rate and tidal volume with exercise and maximal oxygen consumption were apparently the same for both groups (Table 3 ).

\section{Ventilatory response to $\mathrm{CO}_{2}$}

The increase in ventilation during hypercapnia was significantly greater in group $\mathbf{B}$ than in group $\mathbf{R}$, whereas the increase in tidal volume and the threshold of ventilatory response to carbon dioxide appeared to be similar in both groups (Table 3).

\section{Immunological responsiveness}

Only one of the patients in group B tested showed any residual reactivity to an extract of Thermoactinomycetes vulgaris. His response to inhaling the extract before and after inhaling disodium cromoglycate is shown in the Figure. The cromoglycate did not inhibit the response.

\section{Discussion}

This study has shown that a single acute episode of bagassosis can produce a permanent reduction in lung volume and gas transfer, an increase in the ventilatory response to exercise and $\mathrm{CO}_{2}$, and exertional dyspnoea. These changes were mild in these patients and were probably produced by residual fibrosis which had persisted after the acute interstitial granulomatous reaction had resolved (Nicholson, 1965; Reynolds and Stembridge, 1965)

TABLE 2

Lung Volumes and Gas Transfer

\begin{tabular}{|c|c|c|c|c|c|c|c|c|c|c|}
\hline \multirow{3}{*}{ Index } & \multicolumn{5}{|c|}{ Group $B$} & \multicolumn{5}{|c|}{ Group $R$} \\
\hline & \multicolumn{2}{|c|}{ Actual } & \multicolumn{2}{|c|}{ Predicted } & \multirow{2}{*}{$\mathbf{P}$} & \multicolumn{2}{|c|}{ Actual } & \multicolumn{2}{|c|}{ Predicted } & \multirow{2}{*}{$\mathbf{P}$} \\
\hline & Mean & $S D$ & Mean & $R S D$ & & $S D$ & Mean & Mean & $R S D$ & \\
\hline $\begin{array}{l}\text { Forced expiratory volume in } \\
\text { one second }\left(\mathrm{FEV}_{\mathbf{1 . 0}}\right) \text {, } \\
\text { (litres) }\end{array}$ & $2 \cdot 4$ & $0 \cdot 36$ & $2 \cdot 84$ & 0.36 & $<0.001$ & $2 \cdot 48$ & 0.45 & $2 \cdot 63$ & $0 \cdot 36$ & NS \\
\hline $\begin{array}{l}\text { Forced vital capacity } \\
\text { (FVC) (litres) }\end{array}$ & $3 \cdot 04$ & 0.33 & 3.44 & 0.53 & $<0.001$ & $3 \cdot 10$ & 0.46 & $3 \cdot 17$ & 0.53 & NS \\
\hline $\begin{array}{l}\text { Residual volume (RV) (litres) } \\
\text { Transfer factor (TF) (ml/ }\end{array}$ & $1 \cdot 58$ & 0.24 & 1.69 & 0.29 & NS & 1.70 & 0.32 & 1.61 & 0.29 & NS \\
\hline $\begin{array}{l}\text { Transfer factor (TF) (ml/ } \\
\mathrm{min} / \mathrm{mm} \mathrm{Hg} \text { ) }\end{array}$ & 25 & $5 \cdot 6$ & 29 & 4.0 & $\sim 0.001$ & 29 & 5.8 & & $4 \cdot 0$ & NS \\
\hline $\begin{array}{l}\text { Diffusion capacity of alveolar } \\
\text { capillary membrane (Dm) } \\
\text { (ml/min/mm Hg) }\end{array}$ & 42 & 8.9 & 54 & $10 \cdot 0$ & $<0.001$ & 47 & $7 \cdot 6$ & 49 & $10 \cdot 0$ & NS \\
\hline $\begin{array}{l}\text { Alveolar capillary blood } \\
\text { volume }(\mathrm{Vc})(\mathrm{ml})\end{array}$ & 59 & $14 \cdot 8$ & & & & 70 & $19 \cdot 8$ & & & NS \\
\hline
\end{tabular}

RSD = residual standard deviation about the regression line 
TABLE 3

Response to EXerCISE AND HyPERCAPNIA

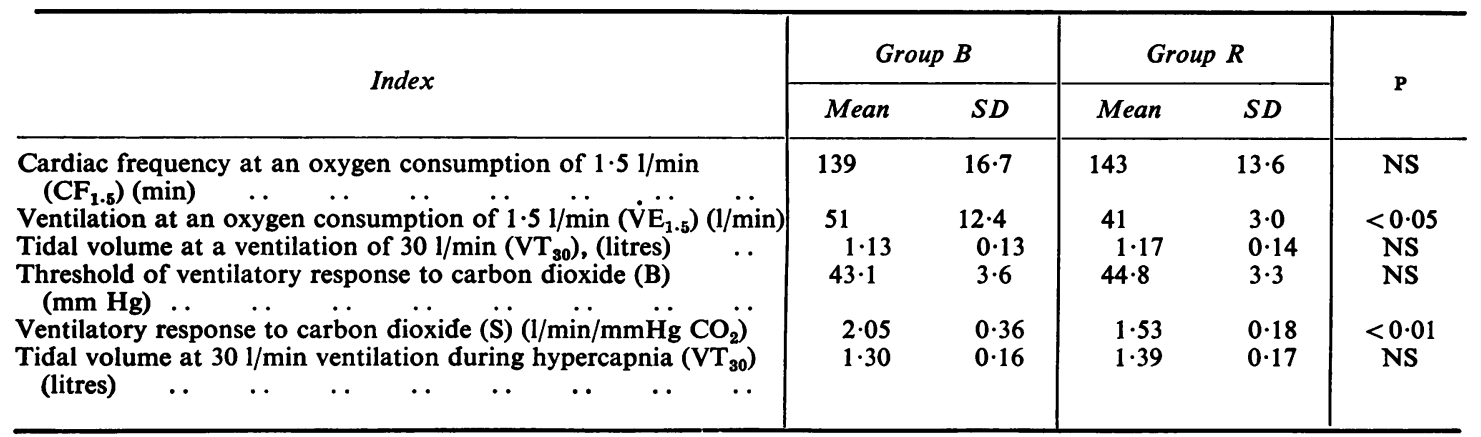

and which was not apparent radiologically. None of the patients studied had a ventilatory limitation of exercise tolerance, this being limited by the magnitude of the circulatory adaptations, although it is likely that there would have been, had exposure to mouldy bagasse dust been prolonged or repeated. More advanced cases would be likely to have radiological pulmonary fibrosis but there are few examples of this in the literature and no cases of this type have been seen in Trinidad. Sensitivity to mouldy bagasse dust can persist for several years after withdrawal from exposure, as in the patient described above.

The concept of a chronic form of bagassosis stems from a report of two cases of pulmonary fibrosis among 11 workers who previously had acute bagassosis (Hunter and Perry, 1946). This might have represented coincident lung disease, for the authors stated that both patients with fibrosis were less exposed to bagasse dust than the patients without fibrosis, and also showed that $13 \%$ of all workers in the factory had pneumoconiosis and $5 \%$ had tuberculosis. Chronic forms of farmer's lung, a similar disorder caused by inhalation of the dust of mouldy hay, are well documented in patients who have suffered recurrent attacks over a number of years (Hapke, Seal, Thomas, Hayes, and Meek, 1968). There is dyspnoea on exertion and chronic cough, chest radiographs show fibrotic changes, and pulmonary function studies reveal either airways obstruction, an interstitial fibrosis pattern, or a combination of both. Pathological studies confirm the presence of fibrotic changes in the lungs (Seal, Hapke, Thomas, Meek, and Hayes, 1968).

The apparent reductions in lung volume described by Weill et al. (1966) some months after clinical recovery from bagassosis were due in part to a failure to allow for ethnic variation. Seventeen of their 20 patients were people of African origin, who have smaller lung volumes than Caucasians (Miller, 1970). Pulmonary function was eventually restored to normal in the majority of their patients, but two patients had persistent airways obstruction four months and seven months after clinical recovery from the acute episode.

As in this study, Pierce et al. (1968) found the diffusion capacity of the alveolar capillary membrane to be a sensitive index of residual damage after bagassosis and stressed the fact that it might be sufficient to limit exercise tolerance at high altitude. Capacity for exercise was reduced in four of their patients three months after withdrawal from exposure to bagasse dust, though it was superior to their performance during the acute illness.

All workers who had been regularly exposed to bagasse dust for several years without developing bagassosis were found to have no impairment of lung function at rest or during exercise two years after the final exposure to the dust. The small reductions in ventilatory capacity produced by exposure to this dusty atmosphere (Hearn, 1968a) would appear to have been reversible and full recovery had occurred with cessation of exposure.

In both groups of subjects the cardiac responses to exercise exceeded those found for Caucasian workers (Cotes, Davies, Edholm, Healy, and Tanner, 1969) and doctors (Edwards, Jones, Oppenheimer, Hughes, and Knill-Jones, 1969a) but were in close agreement with values found for healthy young Trinidadian males of the same ethnic group (Edwards et al., 1969b).

The mechanism of disodium cromoglycate in type III allergy is obscure. Pepys, Hargreave, Chan, and McCarthy (1968) found that when given within 25 minutes of the inhalation test, $20 \mathrm{mg}$ of the drug inhibited the late allergic reactions of three patients with bird-fancier's lung. The time interval between dosage and provocation may be critical for the drug was administered to our patients two and a half hours before the test. However, Altounyan (1970) finds that a significant degree of inhibition to immediate type I reactions persists for about eight 


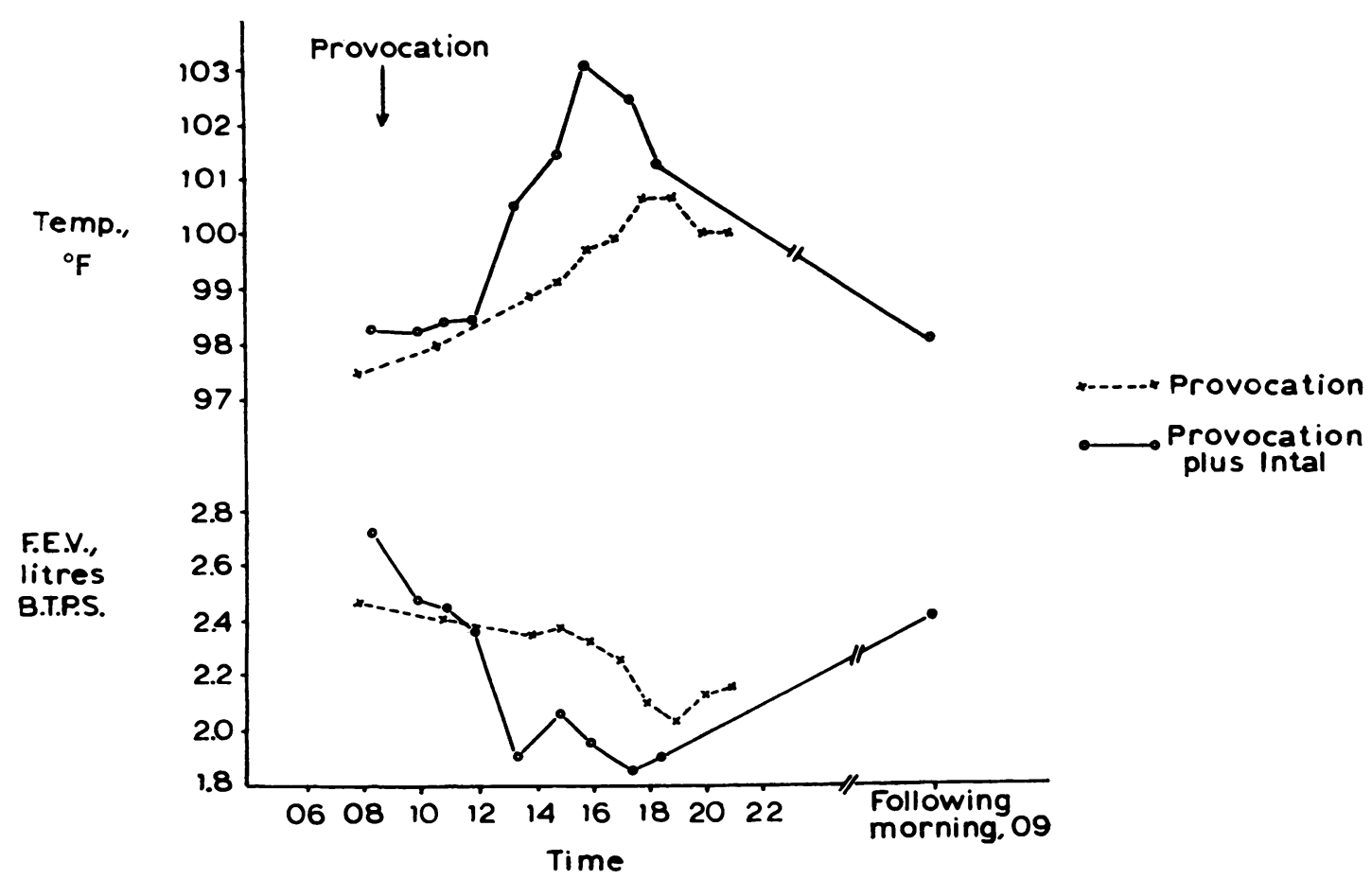

FIGURE. An East Indian man aged 44 years had presented with a four-week history of subacute bagassosis when 38 years old. He was removed from further exposure and recovered fully within seven weeks, both the chest radiograph and his weight returning to normal. Two years after recovery, provocation testing with an extract of Thermoactinomycetes vulgaris produced a well-marked reaction with a pyrexia reaching $100 \cdot 4^{\circ} \mathrm{F}$ six hours after inhalation. There was pronounced malaise with generalized aches and pains and a slight cough. The FEV 1.0 fell from $2 \cdot 76$ to 2.34 litres BTPS and the FVC from 3.03 to 2.60 litres BTPS during the reaction.

Since recovery he has been employed full time as a storeman and has had no further exposure to bagasse. There have been no significant respiratory symptoms or illnesses. Examination on this occasion showed him to be healthy (height $1.61 \mathrm{~m}$, weight $53.9 \mathrm{~kg}$ ) and that the $\mathrm{FEV}_{1.0}$ and $\mathrm{FVC}$ were normal.

Pulmonary gas transfer was rather low because of a reduction in membrane diffusion, although within predicted normal limits. The ventilatory response to exercise was rather high but other indices of pulmonary and cardiac responses to exercise were normal. His temperature rose to $100 \cdot 6^{\circ} \mathrm{F}$ eight hours after inhalational provocation but, unlike four years previously, he experienced no symptoms whatever throughout the reaction. Ventilatory capacity fell transiently at the height of the reaction but gas transfer and the responses to exercise and hypercapnia were essentially unchanged. Provocation was repeated five days later under cover of disodium cromoglycate (Intal) to determine the effect of the drug on type III allergy. Three 20-mg doses were taken daily for two days before the test, and on the test day $20 \mathrm{mg}$ was taken two and a half hours before, and one and a half and six and a half hours after inhalation. This treatment did not suppress the reaction to the antigen.

hours after dosage, so that some inhibition of the late reaction in our subject would be expected if the drug's mechanism of inhibition is similar for both types of reaction. Further studies are necessary to ascertain whether disodium cromoglycate can be used prophylactically to prevent recurrences of symptoms in susceptible subjects when re-exposed to bagasse dust.

Acknowledgements are due to the Medical Research Council; the Department of Medicine, Royal Post- graduate Medical School, London; to the Boards of Directors of Tate and Lyle Limited and Caroni Limited, Trinidad; and to Mr. A. V. Swan, Dr. J. E. Cotes, and the International Biological Programme Sub-committee of the Royal Society for their generous co-operation and support.

\section{References}

Altounyan, R. E. C. (1970). Personal communication. Bailey, N. T. J. (1959). Statistical Methods in Biology. English Universities Press, London. 
Collins, M. M., McDermott, M., and McDermott, T. J. (1964). Bellows spirometer and transistor timer for the measurement of forced expiratory volume and vital capacity. J. Physiol. (Lond.), 172, 39-41 P.

Cotes, J. E., Davies, C. T. M., Edholm, O. G., Healy, M. J. R., and Tanner, J. M. (1969). Factors relating to aerobic capacity of 46 healthy British males and females, ages 18 to 28 years. Proc. roy. Soc. Lond., B, 174, 91-114.

- Johnson, G. R., and McDonald, A. (1970). In Breathing Hering-Breuer Centenary Symposium. Edited by R. Porter. Churchill, London.

Edwards, R. H. T., Jones, N. L., Oppenheimer, E. A., Hughes, R. L., and Knill-Jones, R. P. (1969a). Interrelation of responses during progressive exercise in trained and untrained subjects. Quart. J. exp. Physiol., 54, 394-403.

- Miller, G. J., Hearn, C. E. D., and Cotes, J. E. (1969b). Unpublished data.

Elwood, P. C., and Jacobs, A. (1966). Haemoglobin estimation: a comparison of different techniques. Brit. med. J., 1, 20-24.

Hapke, E. J., Seal, R. M. E., Thomas, G. O., Hayes, M., and Meek, J. C. (1968). Farmer's lung: a clinical, radiographic, functional, and serological correlation of acute and chronic stages. Thorax, 23, 451-468.

Hargreave, F. E., Pepys, J., and Holford-Strevens, V. (1968). Bagassosis. Lancet, 1, 619-620.

Hearn, C. E. D. (1968a). Bagassosis: an epidemiological, environmental, and clinical survey. Brit. J. industr. Med., 25, 267-282.

(1968b). M.D. thesis, London.

- and Holford-Strevens, V. (1968). Immunological aspects of bagassosis. Brit. J. industr. Med., 25, 283-292.

Hunter, D., and Perry, K. M. A. (1946). Bronchiolitis resulting from the handling of bagasse. Brit.J. industr. Med., 3, 64-74.
Meade, F., Saunders, M. J., Hyett, F., Reynolds, J. A., Pearl, N., and Cotes, J. E. (1965). Automatic measurement of lung function. Lancet, 2, 573-575.

. Miller, G. J. (1970). Lung volumes and indices of gas transfer in healthy Jamaican adults of African ethnic origin. In preparation.

Nicholson, D. (1965). Bagasse worker's lung. Amer. Rev. resp. Dis., 92, 327.

Pepys, J., Hargreave, F. E., Chan, M., and McCarthy, D. S. (1968). Inhibitory effects of disodium cromoglycate on allergen-inhalation tests. Lancet, 2, 134-137.

Pierce, A. K., Nicholson, D. P., Miller, J. M., and Johnson, R. L. (1968). Pulmonary function in bagasse worker's lung disease. Amer. Rev. resp. Dis., 97, 561-570.

Read, D. J. C. (1967). A clinical method of assessing the ventilatory response to carbon dioxide. Aust. Ann. Med., 16, 20-32.

Reynolds, R. C., and Stembridge, V. A. (1965). Electron microscopy of bagassosis in humans. Amer. Rev. resp. Dis., 92, 327-328.

Roughton, F. J. W., and Forster, R. E. (1957). Relative importance of diffusion and chemical reaction rates in determining rate of exchange of gases in the human lung. J. appl. Physiol., 11, 290-302.

Seal, R. M. E., Hapke, E. J., Thomas, G. O., Meek, J. C., and Hayes, M. (1968). The pathology of the acute and chronic stages of farmer's lung. Thorax, 23, 469-489.

Weill, H., Buechner, H. A., Gonzalez, E., Herbert, S. J., Aucoin, E., and Ziskind, M. M. (1966). Bagassosis: a study of pulmonary function in 20 cases. Ann. intern. Med., 64, 737-747.

Weiner, J. S., and Lourie, J. A. (1969). Human Biology. A Guide to Field Methods. Blackwell Scientific Publications, Oxford.

Williams, J. V. (1963). Inhalation and skin tests with extracts of hay and fungi in patients with farmer's lung. Thorax, 18, 182-196.

Received for publication May 18, 1970. 